\title{
Seguridad e Ideología en Colombia, 1978-1982: análisis crítico del discurso de Julio César Turbay Ayala*
}

\section{Resumen}

En el presente artículo analizamos el uso del concepto seguridad en el discurso del presidente colombiano Julio César Turbay Ayala (1978-1982). Este concepto, visto como categoría político-militar, es puesto en una perspectiva histórico-contextual, nacional e internacional, con el objetivo de aclarar cómo se configuraron los sistemas de representación y orientación socio-cognitiva, así como la ambigüedad que lo circundó. Del mismo modo, ofrecemos un ejercicio hermenéutico y un enfoque descriptivo que permite comprender cómo las relaciones entre discurso, contexto e ideología posibilitaron su implementación y rediseño, además, cómo ellas, al final, entraron a justificar diversas medidas en función del restablecimiento del orden y la moral pública en el marco de la denominada Seguridad Nacional.

Palabras clave: Colombia, Estado de sitio, seguridad, paz, ideología.

Referencia para citar este artículo: RAMÍREZ BACCA, Renzo y MARÍN ARENAS, León Darío (2015). "Seguridad e Ideología en Colombia, 1978-1982: análisis crítico del discurso de Julio César Turbay Ayala". En Anuario de Historia Regional y de las Fronteras. 20 (2). pp. 241-269.

Renzo Ramírez Bacca: Historiador, Mg. y PhD en Historia de la Universidad de Goteburgo (Suecia). Profesor Titular adscrito a la Facultad de Ciencias Humanas y Económicas de la Universidad Nacional de Colombia, Sede Medellín, e Investigador Sénior (SI) del Grupo de Investigación "Historia, Trabajo, Sociedad y Cultura". Participó como Director del proyecto en mención. Correo electrónico: rramirezb@ unal.edu.co.

León Darío Marín Arenas: Politólogo por la Universidad Nacional de Colombia, Sede Medellín. Historiador en formación por la misma universidad y miembro de la Asociación de Politólogas y Politólogos de Antioquia. Participó en calidad de auxiliar de investigación en el proyecto "Discurso y Representaciones de la Guerra y la Paz en Colombia, 1978-2006”. Correo electrónico: 1dmarina@unal.edu.co.

\footnotetext{
*Artículo de reflexión derivado del proyecto de investigación "Discurso y Representaciones de la Guerra y la Paz en Colombia, 1978-2006”, con código Hermes 2010100 y financiado por la Vicerrectoría de Investigaciones de la Universidad Nacional de Colombia.
} 


\title{
Security and Ideologies in Colombia, 1978-1982: analysis from the discourse of Julio Cesar Turbay Ayala
}

\begin{abstract}
We analyze the concept of security in the discourse of President Julio Cesar Turbay Ayala (1978-1982) in Colombia. That term, seen as a political-military category, is placed in a historical-contextual perspective -local and international-in order to clarify how the representation and socio-cognitive guidance systems were configured, as well as it also analyzes the ambiguity it had. Likewise, we offer an hermeneutical exercise and a descriptive approach, that allows understanding how the relationships between discourse, context and ideology, made it possible to deploy and redesign that term; and how those relationships, in the end, brought a justification several measures in order to restore the order and public moral within the framework of the said National Security.
\end{abstract}

Keywords: Colombia, a state of siege, security, peace, ideology.

\section{Segurança e Ideologia na Colômbia, 1978-1982: Análise desde o discurso de Julio Cesar Turbay Ayala}

\begin{abstract}
Resumo
Analisamos o uso do conceito segurança no discurso do presidente Julio César Turbay Ayala (1978-1982) na Colômbia. O termo, visto como categoria político-militar, é colocado em uma perspectiva histórico-contextual -nacional e internacional-com o objetivo de esclarecer como foram configurados os sistemas de representação e orientação sócio-cognitiva, assim como a ambiguidade que o cercou. Igualmente, oferecemos um exercício hermenêutico e um enfoque descritivo, que permite compreender como as relações entre discurso, contexto e ideologia possibilitaram sua implementação e redesenho; e como elas, ao final, entraram a justificar diversas medidas em função do restabelecimento da ordem e da moral pública no marco da denominada Segurança Nacional.
\end{abstract}

Palavras-chave: Colômbia, o estado de sítio, a segurança, a paz, a ideologia. 


\section{Introducción}

Colombia es uno de los países que más ha sufrido el flagelo de la violencia a escala mundial durante el siglo XX. Un fenómeno que vive la sociedad de modo cíclico con diversos matices, elementos y fases nacionales e internacionales, por causa de distintos aspectos, por ejemplo: las distintas concepciones de Estado, seguridad y desarrollo; los efectos de procesos y circunstancias externas como la Gran Guerra y la Segunda Guerra Mundial y sus dinámicas (modernización del Estado, homogenización económica y militar por parte de los Estados Unidos de América y movimiento comunista internacional auspiciado por la antigua Unión Soviética); la Guerra Fría y fenómenos recientes como el narcotráfico ${ }^{1}$. Sin embargo, la sociedad pareciera no tener una consciencia histórica de su contexto y antecedentes, razón que nos motiva a presentar este artículo. No para investigar los daños morales, económicos y sociales causados por los violentos, pero sí para analizar su doctrina, discursos y cómo se puede entender el fenómeno a la luz de la historia política reciente.

Nos centraremos entonces en el caso específico del discurso de Julio César Turbay Ayala y la problemática de la "seguridad" durante su gobierno de (1978-1982); cuando el país estuvo bajo el denominado Estado de Sitio, mecanismo constitucional, apoyado en el Artículo 121 de la Constitución de 1886, cuya jurisprudencia sirvió al establecimiento político-militar colombiano. Es preciso tener en cuenta que entre 1974 y 1991, la sociedad colombiana experimentó trece años bajo Estado de Sitio. En un período en que Latinoamérica vivía cruentas dictaduras militares, pero que la historiografía colombiana no ha comparado ni tampoco relacionado. Si bien estos fenómenos políticos de talante militarista son distintos, tienen en común que se presentaron durante la Guerra Fría. Razón por la cual queremos contextualizar y analizar el impacto de la Doctrina de Seguridad Nacional estadounidense en América Latina.

En consecuencia, la pregunta inicial es: ¿cuáles fueron las representaciones discursivas en materia de seguridad y su relación con el contexto nacional e internacional? Para ofrecer nuestra comprensión, nos apoyamos en un análisis del discurso presidencial (alocuciones oficiales); de igual modo, en la técnica hermenéutica para identificar el contexto socio-político y económico del período de estudio; además, en diversas fuentes secundarias sobre la problemática colombiana y en ciertas herramientas conceptuales, tales como, discurso, contexto, ideología y seguridad.

El discurso, entendido como acto comunicativo, supone la interacción social de un conjunto de elementos que configuran, ordenan y dan sentidos a las realidades. Por esta razón se presenta como "[...] un fenómeno que produce unos efectos determinados y que posee unas reglas de formación que lo hacen surgir, que no son casuales ni

\footnotetext{
${ }^{1}$ No obstante, la memoria reciente parece limitarse solo a las víctimas y los victimarios de esas olas de violencia. Las cifras lo indican: ocho guerras civiles y 80000 muertes durante el siglo XIX, 100000 víctimas durante la Guerra de los Mil Días (1899-1902); entre 1946 y 1957 se habla de 200000 muertes por la violencia bipartidista y cerca de 2000000 de "refugiados políticos". Otras 220000 muertes entre 1958 y 2012, 5700000 víctimas por desplazamiento entre 1986 y 2012, 25000 desparecidos en el mismo período y 30000 secuestrados entre 1970 y 2010 .
} 
neutras"2; reglas que condensan estructuras de percepción del mundo y contienen sistemas de representación, desde los cuales se produce y expresa la identidad de los actores sociales de un momento histórico determinado. Dichas consideraciones proponen el discurso como un agente dinámico que, en términos de Foucault, está mediado por diferentes procedimientos internos y externos que se apoyan en factores de poder de un contexto específico. Los procedimientos internos implican lo que se puede decir en un momento dado y quién está facultado para decirlo, mientras que los procedimientos externos se configuran como los intereses de los grupos de presión que buscan posicionar un mensaje sobre otro, las posibilidades de acceso a los medios de comunicación, etcétera ${ }^{3}$.

El contexto, más allá de la utilización informal del término y su contenido, se encuentra estrechamente vinculado a las nociones de discurso e ideología. Pardo y Rodríguez lo relacionan también con la situación social o conjunto de conocimientos relevante para la producción e interpretación del discurso ${ }^{4}$. Los contextos pueden ser vistos entonces como constructos mentales y representaciones sociales, en relación con conocimientos comunes, actitudes e ideologías. No por otra razón el análisis crítico del discurso exige una postura interdisciplinaria ${ }^{5}$, que en nuestro enfoque se relaciona con nuestra comprensión desde la historia, la ciencia política y la sociología.

Respecto del discurso y contexto es necesario considerar el concepto de ideología, toda vez que en el contexto de la Guerra Fría (1947-1991), este se constituyó como parte de la estrategia e identidad discursiva de los actores y factores que incidieron en los distintos grupos sociales, sus valores socioculturales y autodefiniciones grupales ${ }^{6}$. De esta manera, en consideración de los postulados de Noelia Buen ${ }^{7}$, tomamos la ideología como proporcionadora de un discurso que pretende explicar y comprender el mundo.

El concepto de seguridad, constituyente del análisis de las piezas discursivas del presidente Julio César Turbay Ayala (1978-1982), lo entendemos como una estrategia para justificar las acciones del Estado con relación a la estructuración de la política de seguridad nacional. De hecho, Buzan advierte que ese recurso es una justificación para acciones y políticas en medio de intereses sectoriales en todo tipo de estados; además, en el caso de no ser una noción claramente definida "facilita estrategias maximalistas del poder para las élites políticas y militares"

\footnotetext{
${ }^{2}$ BETHENCOURT, María y AMODIO, Emanuele, Lenguaje, ideología y poder, Caracas, Instituto internacional para la educación superior en América Latina y el Caribe (IESALC)-Unesco, 2006, p. 67.

${ }^{3}$ FOUCAULT, Michel, El orden del discurso. [Traducción de Alberto González Troyano], Lección inaugural en el Collège de France, Buenos Aires, Tusquets editores, 1992.

${ }^{4}$ PARDO ABRIL, Neyla Graciela y RODRÍGUEZ, Aleyda, "Discurso y Contexto: cognición y subjetividad”, en Discurso \& Sociedad, Vol. 3, No. 1, 2009, p. 207.

${ }^{5}$ PARDO ABRIL, Neyla Graciela, "Análisis Crítico del Discurso: un acercamiento a las representaciones sociales”, en Forma y Función, No. 12, 1999, p. 64.

${ }^{6}$ VAN DIJK, Teun, “Semántica del discurso e ideología”, en Discurso \& Sociedad, Vol. 2, No. 1, 2008, p. 208. ${ }^{7}$ BUENO GÓMEZ, Noelia, "Crítica de la ideología de Marx", en Eikasia. Revista de Filosofia, Vol. III, No. 13, 2007, pp. 45-90.

${ }^{8}$ BUZAN, Barry, "People, States \& Fear: An Agenda for International Security Studies in the post-cold War
} 
ambigüedad natural de las amenazas extranjeras durante períodos de paz, facilita el encubrimiento de intenciones más siniestras bajo la capa de la seguridad nacional". Por su parte Wæver,, citado por Møller, previene sobre los inconvenientes de la excesiva seguritización, cuando se eleva cualquier situación al estatus de "problema de seguridad"; por lo cual en el discurso político cualquier problema de este tipo “puede tender al (ab) uso de una 'prohibición' de ciertos asuntos y a la marginación de oponentes ideológicos"s.

En tal escenario analítico se fundamentó la Política de Seguridad Nacional (PSN) estadounidense, la cual se convirtió en la política internacional más relevante posterior a la Segunda Guerra Mundial. En su ejecución, esta tuvo variantes significativas, una de ellas es precisamente la que enmarcó las relaciones entre Estados Unidos y América Latina: la Doctrina de Seguridad Nacional (DSN) ${ }^{10}$. Ahora bien, ¿qué se entiende por DSN?, ¿en qué contexto latinoamericano se fraguó la instrumentalización de esta política respecto de América Latina, particularmente en Colombia? Además, ¿qué noción de seguridad se instaló en la política Estatuto de Seguridad desde el discurso del presidente Turbay Ayala? Estos interrogantes, conjugados con las anteriores anotaciones teórico-conceptuales, son el marco referente para desarrollar el siguiente análisis.

\section{Doctrina de Seguridad Nacional: una estrategia política y militar para América Latina}

Buzan propone diversas rutas para comprender el "subdesarrollo del concepto seguridad" durante gran parte del siglo XX. Una de ellas permite estructurar de manera sistemática una interpretación respecto de los entramados conceptuales y las representaciones que subyacen a la acción discursiva de la Doctrina de Seguridad Nacional (DSN). Se señala que la Guerra Fría se enmarcó en el sostenimiento de la "ambigüedad simbólica del concepto seguridad" y posibilitó, en medio de la elasticidad de su comprensión y uso, o bien llevar a cabo acciones políticas para el bienestar general de los asociados, o bien justificar - bajo circunstancias específicas- la necesidad de instaurar "medidas coercitivas para preservar los intereses nacionales"

Partamos de una diferenciación contextual en torno a la seguridad como la categoría política de mayor impacto en el siglo XX. En ese sentido, se observa un cambio entre las acciones en materia de seguridad de la primera mitad del siglo XX y las efectuadas a partir de 1950. Básicamente de la guerra estrictamente de confrontación militar (dada hasta la Segunda Guerra Mundial), se pasó a la Guerra Fría como escenario caracterizado por generar un ambiente de incertidumbre, alarmismo e indecisión, que permitió instaurar el concepto geopolítico de "guerra total". En el marco de la

Era. Introducción y Capítulo 10”, en Revista Académica de Relaciones Internacionales, No. 9, 2008, p. 11.

${ }^{9}$ MØLLER, Bill Norge, “Conceptos sobre seguridad: nuevos riesgos y desafíos”, en Desarrollo Económico: Revista de Ciencias Sociales, Vol. 36, No. 143, 1996, p. 771.

${ }^{10}$ LEAL BUITRAGO, Francisco, La Seguridad de la Inseguridad. Colombia 1958-2005, Bogotá, Editorial Planeta, 2006, p. 27.

${ }^{11}$ BUZAN, Barry, Op cit. 
Guerra Fría, la contienda no solo era bélica, sino que yacía en los campos económico, financiero, político, psicológico, científico y tecnológico ${ }^{12}$. Las políticas concretas se efectuaron sobre la base de la creación y sostenimiento de distintas estrategias, sobre todo político-militares, que tenían como fundamento una noción clara y puntual. Según Orozco, estas estrategias permiten "[...] disponer de todos los medios indispensables (normalmente militares), así como los recursos necesarios para preservar el interés de la nación, pues con ello se logrará mantener la integridad y librar de las amenazas a aquellos intereses prioritarios del Estado"13.

Velásquez señala que la DSN surge como conjunto de concepciones y cuerpo de enseñanza derivado de supuestas verdades, principios, normas y valores, es decir, un presupuesto ideológico estructurado, que un Estado a través de sus propias experiencias o las de otros Estados - de conformidad con su Constitución Política y con las realidades del país, fundamentos para el diseño y ejecución del poder-considera que se debe llevar a la práctica para garantizar el desarrollo integral del hombre y de la colectividad nacional como plataforma discursiva ${ }^{14}$. Lo anterior erigió un horizonte claro de lo que identificaría la política de seguridad del continente americano, con el liderazgo de Estados Unidos, por lo que Leal advierte que fue:

[...] el mayor esfuerzo latinoamericano por militarizar el concepto de seguridad. Además, al ubicar el componente militar en el centro de la sociedad, trascendiendo las funciones castrenses, la Doctrina se convirtió en la ideología militar contemporánea de mayor impacto político en la región ${ }^{15}$.

Comprender el ejercicio de tales disposiciones doctrinales exige presentar las estrategias desarrolladas. La primera, según Leal, se ubica entre 1945 y 1950, a partir de dos hechos: por una parte, la promulgación del Acta de Seguridad Nacional estadounidense de 1947, por medio de la cual se crearon el Consejo de Seguridad Nacional (CSN) y la Agencia Central de Inteligencia (CIA), ${ }^{16}$ instituciones encargadas del diseño estratégico de la política de seguridad nacional estadounidense. Y de otro lado, la difusión de la concepción de seguridad nacional en la región, a partir de la firma de diferentes tratados de integración política, jurídica y militar en defensa de la soberanía y la integridad territorial de los estados americanos ${ }^{17}$.

\footnotetext{
12 VELÁSQUEZ RIVERA, Edgar de Jesús, "Historia de la Doctrina de Seguridad Nacional", en Convergencia, Año 9, No. 27, 2002, pp. 11-39.

${ }^{13}$ OROZCO RESTREPO, Gabriel, "El aporte de la escuela de Copenhague a los estudios de seguridad", en Revista Fuerzas Armadas y Sociedad, Vol. 20, No. 1, 2006, pp. 145-146.

${ }^{14}$ VELÁSQUEZ RIVERA, Edgar de Jesús, Op cit., pp. 11-39.

${ }^{15}$ LEAL BUITRAGO, Francisco, "La Doctrina de Seguridad Nacional: Materialización de la Guerra Fría en América del Sur”, en Revista de Estudios Sociales, No. 15, 2003, p. 75.

${ }^{16}$ LEAL BUITRAGO, Francisco, "Surgimiento, Auge y Declinación de la Doctrina de Seguridad Nacional en América Latina y Colombia", en LEAL BUITRAGO, Francisco, El oficio de la guerra. La seguridad nacional en Colombia, Bogotá, TM Editores-IEPRI-Universidad Nacional de Colombia, 1994.

${ }^{17}$ Dentro de los pactos y tratados se encuentran: el Acta de Chapultepec (1945), el Plan Truman (1946), el Tratado Interamericano de Asistencia Recíproca (1947) y la Organización de Estados Americanos -OEA(1948). En otra latitud, se creó en 1949 el Tratado del Atlántico Norte (OTAN), que actuó igualmente como táctica de presencia y prevención a las posibles agresiones de la Unión de Repúblicas Socialistas
} 
La segunda estrategia se basa en la creación de instituciones encargadas de formar (adoctrinar) la oficialidad y suboficialidad militar latinoamericana: la Escuela Militar de las Américas (US Army School of the Americas, USARSA) ${ }^{18}$, la Academia Interamericana de las Fuerzas Aéreas, la Universidad del Aire, la Escuela para Comandantes de Escuadrón, la Academia de Guerra Aérea, la Academia de Comandos y Estado Mayor, la Academia de Guerra Naval y la Academia Interamericana de Policía ${ }^{19}$.

Finalmente, la tercera estrategia contempló la diferenciación explícita entre "enemigo externo" y "enemigo interno". Mientras a Estados Unidos le correspondía combatir a la URSS y a Cuba, como epicentros visibles del comunismo (enemigo externo), los estados latinoamericanos debían enfrentar al enemigo interno, materializado en supuestos agentes locales: “[...] además de las guerrillas, el enemigo interno podía ser cualquier persona, grupo o institución nacional que tuviera ideas opuestas a las de los gobiernos militares" ${ }^{\prime 20}$.

Como resultado del despliegue intervencionista norteamericano, y su labor doctrinal, se presenció una mayor inestabilidad democrática en la región en el período 19601990. La instauración de dictaduras militares y cívico-militares, en gran parte de los estados latinoamericanos, presentó una discordante relación discursiva entre salvaguardar el interés nacional y el resquebrajamiento de los principios fundantes del sistema democrático occidental, del cual Estados Unidos fue uno de sus precursores. Lo evidente es la inconsistencia entre discurso y acción, en la medida en que no existió una relación lógica de causalidad entre el discurso sobre "asegurar el interés nacional" y el accionar de los estados en la "promoción de los valores democráticos", por tanto, el factor ideológico se tornó central, al presentarse como dispositivo de poder que orientó la cognición social hacia un "canon de verdad" sobre la necesidad de seguritizar el interés nacional, así significara el desmonte directo de la democracia en América Latina.

Según Velásquez, entre 1962 y 1982 se presentaron once golpes de estado en los cuales hubo incidencia estadounidense, nueve fueron ejecutados en la década 1960, uno en la de 1970 y otro más en la de 1980. En los casos de Uruguay (1973-1985) y Paraguay (1954-1989), donde también se instalaron gobiernos militares en el mismo período, los procesos de instauración dictatorial difirieron de los Golpes de Estado que afrontaba la región y se orientaron bajo estrategias furtivas de acuerdos entre los dirigentes políticos de turno y los altos mandos militares (conocidas como dictaduras cívico-militares $)^{21}$.

Soviéticas-URSS. LEAL BUITRAGO, Francisco, Op cit., pp. 20-21.

${ }^{18}$ Velásquez señala que "en 1975 se habían graduado 33147 alumnos en la USARSA, muchos de ellos ocuparon altos cargos en sus gobiernos. En octubre de 1973, más de 170 graduados eran jefes de gobierno, ministros, comandantes, generales o directores de los departamentos de inteligencia de sus respectivos países. Los golpes de Estado en Perú, Bolivia, Panamá y Chile, fueron llevados a cabo por los más aplicados oficiales que habían asistido a la USARSA". VELÁSQUEZ RIVERA, Edgar de Jesús, "Historia de la Doctrina de Seguridad Nacional”, en Convergencia, Año 9, No. 27, 2002, p. 17.

${ }^{19}$ Ibid., pp. 17-19.

${ }^{20}$ LEAL BUITRAGO, Francisco, "La Doctrina de...", Op. cit., p. 14.

${ }^{21}$ VELÁSQUEZ RIVERA, Edgar de Jesús, Op cit., p. 20. 
Como política, la noción seguridad nacional dictada por Estados Unidos, forjó un contexto de interacción particular en el hemisferio occidental. Sin embargo, lo que se denomina "Doctrina de Seguridad Nacional" - diferente de la Política de Seguridad Nacional ${ }^{22}$ estadounidense- debe considerarse no como fórmula o cuerpo sistematizado de acciones a ser aplicado, sino como un fenómeno derivado de un contexto, que proveyó una serie de disposiciones respecto de la forma de asumir las tensiones bipolares de la Guerra Fría en América Latina. Por lo tanto, como fenómeno, la DSN presenta una serie de manifestaciones con diferentes grados de intensidad, que sirvieron de base para identificarla y entenderla. De ahí el carácter disímil de los gobiernos dictatoriales en América Latina y la variabilidad en la ejecución de los principios orientadores de ella. Analicemos entonces el caso colombiano y su política de seguridad en esos años.

\section{Política de seguridad en el Estatuto de Seguridad colombiano}

El contexto a partir del cual se insertó Colombia a las dinámicas del continente tiene sus propios matices. Para comprender el despliegue de la DSN, su influencia en la cristalización del Estatuto de Seguridad turbayista (1978) y las nociones de seguridad que de allí derivan, es necesario dar cuenta de los antecedentes y principales eventos que fueron gestando una estrecha relación entre los estamentos político y militar en el país ${ }^{23}$.

El primer antecedente lo constituye el período de La Violencia en Colombia (19481958), denominado así por la intensidad de los enfrentamientos hostiles y sangrientos entre liberales y conservadores, tras el asesinato del candidato presidencial Jorge Eliécer Gaitán el 9 de abril de 1948. "Sin haberse declarado una guerra civil [este período] se caracterizó por ser extremadamente violento, incluyendo asesinatos, agresiones, persecuciones, destrucción de la propiedad privada y terrorismo por el alineamiento político"224. Los acontecimientos del período de La Violencia acarrearon consecuencias que transformaron el país ${ }^{25}$.

Un segundo evento, esta vez desde el plano internacional y en torno a la modernización de las instituciones militares colombianas, lo constituye la expedición del Decreto 3297 de 1950 y el 1967 de 1951, que formalizaron la conformación del Batallón Colombia No. 1, único apoyo latinoamericano directo en la Guerra de Corea (1951-1954).

\footnotetext{
${ }^{22}$ Una mayor comprensión respecto de la diferencia entre la "política de seguridad nacional" de Estados Unidos y la "Doctrina de Seguridad Nacional" forjada al interior de América Latina se encuentra en LEAL BUITRAGO, Francisco, "Surgimiento, Auge...", Op. cit., pp. 11-65.

${ }^{23}$ Una revisión conceptual en torno al conflicto colombiano en las últimas décadas puede verse en: RAMÍREZ BACCA, Renzo y JIMÉNEZ PATIÑO, Hernán David, “Guerra y paz: una revisión conceptual. Una interpretación para el caso colombiano”, en Historia Caribe, Vol. IX, No. 24, 2014, pp. 163-197.

${ }^{24}$ SAlamanCA, José Manuel, Violencia Politica y Modelos Dinámicos: un estudio sobre el caso colombiano, Colombia, Editorial Alberdania, 2007, p. 34.

25 JIMÉNEZ, Catalina, “Aplicación e instrumentalización de la Doctrina de Seguridad Nacional en Colombia (1978-1982): efectos sobre la temática de derechos humanos", en Reflexión Política, Vol. 11, No. 2, 2009, pp. 161-162.
} 
Respecto de la transformación de la institución castrense en el país y su participación en la guerra coreana, Schroeder plantea que "[...] sirvieron para transformar, modernizar y re-profesionalizar al Ejercito de Colombia [e] influyó de manera significativa en la construcción de la nueva mentalidad del Ejército Nacional'"26.

La participación de Colombia en la guerra permitió que altos mandos oficiales -Alberto Ruiz Novoa, Álvaro Valencia Tovar, Fernando Landazábal, entre otrosadquirieran nociones, conocimientos y posturas anticomunistas, que avivaron el ideal según el cual las Fuerzas Militares de Colombia (FF. MM.) se asumieron como "[...] la institución encargada de garantizar la normalidad contra los enemigos externos e internos y la única que está en condiciones de hacerlo en momentos de crisis"27. Básicamente con el regreso del Batallón Colombia de la guerra de Corea en 1954, las enseñanzas y prácticas militares empezaron a ser utilizadas en el país, dando paso a una concepción pronorteamericana, la cual como ideología contenía una visión bipolar del mundo con el liderazgo de Estados Unidos (EE.UU.) en occidente, representante del " [...] bien, la civilización, la democracia y el progreso; mientras que la entonces Unión Soviética estaba en el eje del mal, el atraso y la dictadura"28. Lo anterior llevó a un intervencionismo militar autorizado sobre lo político entre 1953 y $1958^{29}$, como alternativa para frenar la violencia bipartidista que seguía desangrando al país.

Finalizado el período de la Junta Militar de Gobierno (1957-1958) identificamos un tercer evento: el acuerdo político conocido como Frente Nacional; una coalición política de alternancia gubernamental entre los dos partidos, liberal y conservador, durante 16 años equivalentes a cuatro períodos presidenciales entre 1958 y 1974, dos para cada partido; esto puso fin a la violencia política bipartidista.

Durante el Frente Nacional disminuyó el papel militar en la esfera dirigente del Estado, al tiempo que se redefinió la institución castrense. Esto conllevó a un protagonismo aún mayor de las Fuerzas Armadas en las décadas siguientes, lo que representa el cuarto evento. La potenciación de la institución militar con apoyo norteamericano se constituye como uno de los logros más notorios ${ }^{30}$, puesto que facilitó: primero, la creación del Consejo Superior de Defensa Nacional en 1960; segundo, la fundación de

\footnotetext{
${ }^{26}$ SCHROEDER GONZÁLEZ, Cristian, La influencia de la Participación de Colombia en la Guerra de Corea en la construcción de la nueva mentalidad del ejército entre 1951 hasta 1982, Monografía para optar al título de Politólogo, Bogotá, Universidad Colegio Nuestra Señora del Rosario, 2009, p. 26.

${ }^{27}$ LEAL BUITRAGO, Francisco, “Surgimiento, Auge...”, Op. cit., p. 47.

${ }^{28}$ VELÁSQUEZ RIVERA, Edgar de Jesús, Op cit., p. 13.

${ }^{29}$ Con ayuda de la apoliticidad militar formal, hubo resistencia institucional para tomar partido en la contienda, lo cual facilitó la continuidad de la subordinación castrense a los gobiernos civiles. Incluso, las presidencias militares del General Rojas Pinilla (1953 y 1957) y la Junta Militar (1957 y 1958) fueron el resultado de coaliciones bipartidistas que las indujeron directamente. Ver LEAL BUITRAGO, Francisco, "Surgimiento, Auge...", Op. cit., p. 45.

${ }^{30}$ El apoyo a la acción cívico-militar iniciada con el Plan Lazo procedió principalmente de la Ayuda Estadounidense (USAID) y del Mutual Aid Program (MAP). Entre 1961 y 1967 Colombia recibió 60 millones de dólares, como parte del Acuerdo de Asistencia Militar con Estados Unidos, firmado en 1952. También le fueron consignados 430 millones para asistencia económica provenientes de la Alianza para el Progreso. LEAL BUITRAGO, Francisco, La Seguridad de la ..., Op. cit., 2006.
} 
la Revista Fuerzas Armadas (1960) y la Revista Ejército (1961); tercero, la enseñanza en los cursos de ascenso que, junto con las revistas mencionadas, se convirtieron en el principal medio de difusión de una teorización nueva ${ }^{31}$, es decir, la difusión de nuevas concepciones del actuar militar; y cuarto, un proceso de modernización y profesionalización ${ }^{32}$. Con esto el papel militar se entronizaría y sintonizaría con mayor vehemencia en la vida nacional.

En esa medida, un quinto evento a considerar es producto de la segunda etapa de violencia política en el país: si bien el acuerdo del Frente Nacional dispuso una calma relativa al conflicto político bipartidista; la década de 1960 se presenta como el inicio de otro período de conflicto armado interno, por cuenta de la fundación de grupos guerrilleros de izquierda, los cuales derivaron del contexto de la Guerra Fría, fundamentados bajo los eventos de la Revolución Cubana (1959).

Con el surgimiento de estos grupos entre 1960 y 1980 -las Fuerzas Armadas Revolucionarias de Colombia en 1964, el Ejército de Liberación Nacional en 1964, el Ejército Popular de Liberación en 1967, el Movimiento 19 de abril (M-19) en 1974, entre otros-, la crisis nacional se ahondó, permitiendo la reconfiguración de las instituciones encargadas de restablecer y salvaguardar el orden público nacional. Así, las fuerzas militares establecieron un patrón ideológico anticomunista, que acentuó la Guerra Fría en Colombia y que llenó el vacío dejado por el proceso de despolitización de los militares con respecto al bipartidismo ${ }^{33}$.

Olarte señala que este relleno ideológico por parte de las fuerzas militares iba en consonancia con los postulados regionales de la Doctrina de Seguridad Nacional suramericana, al considerar "[...] la mayor parte de los problemas sociales como manifestaciones subversivas. Esto se convirtió en una especie de "razón social" o criterio utilizado por varios sectores sociales para identificar, generalmente, algunas connotaciones ideológicas o fines políticos"34.

En el escenario colombiano no se logró estructurar una política de seguridad y defensa nacional sistemática y sostenible en el tiempo. Solo se llegó a la expedición de medidas contingentes que actuaban sobre la inmediatez, mas no sobre la planificación a largo plazo. De ahí directrices como el Decreto 3398 de 1965, llamado Estatuto para la

\footnotetext{
${ }^{31}$ GILHODÉS, Pierre, "El ejército colombiano analiza la violencia”, en SÁNCHEZ GÓMEZ, Gonzalo, PEÑARANDA, Ricardo (Comp.), Pasado y presente de la violencia en Colombia, Medellín, La Carreta Histórica, 2007, p. 303.

32 Schroeder plantea ocho conductas que fueron interiorizadas por las fuerzas militares colombianas tras la participación en la Guerra de Corea y que configuraron un nuevo imaginario de esta institución: 1) Importancia moral, 2) Inteligencia y Contra inteligencia, 3) Acción psicológica, 4) Realización de operaciones, 5) Logística, 6) Guerra de guerrillas, 7) Armamento y comunicaciones, 8) Organización del Estado Mayor. Ver: SCHROEDER GONZÁLEZ, Cristian, Op cit., pp. 30-35.

${ }^{33}$ LEAL BUITRAGO, Francisco, La Seguridad de la ..., Op. cit., p. 60.

${ }^{34}$ OLARTE NIÑO, Tamanai, Estado, políticas de seguridad y derechos humanos en Colombia 1978-1982 y 2002-2006, Monografía para optar al título de especialista en Derechos Humanos, Bogotá, ESAP, 2008, p. 6. Léase también JIMÉNEZ, Catalina, Op cit., pp. 164-165.
} 
Defensa Nacional; la Ley 48 de 1968, que elevó dicho Estatuto en norma permanente; y el Decreto 1573 de 1974, el cual completó la matriz que orientó los escasos planes de seguridad nacional hasta finales del siglo $\mathrm{XX}^{35}$.

Paralelo al proceso de modernización y profesionalización de la institución militar, se presenta un último evento (instrumento) de gran resonancia política en el ámbito nacional, que suministró herramientas para comprender la inserción de los postulados de la DSN y su cristalización en políticas como el Estatuto de Seguridad en el período $1978-1982^{36}$.

Teóricamente, el Estado de Sitio se asumió en la Carta de 1886 como mecanismo de defensa y seguridad nacional, con un esquema de facultades constitucionales concatenadas en el Artículo 121, el cual permitía la adopción de medidas extraordinarias en procura del restablecimiento del orden público interno o para hacer frente a una guerra exterior por parte del ejecutivo. Sin embargo, en la práctica y sobre todo a partir del período de violencia bipartidista de mitad de siglo XX, la excepcionalidad perdió su naturaleza y se convirtió en regla permanente; con lo cual, en palabras de Ochoa Gautier:

[...] invocar la idea de crisis en relación a Colombia significaba nombrar, más que un estado de excepción, un estado de normalidad; o por lo menos, de cíclico retorno de 'lo crítico' bajo diferentes rostros, todos ellos enmarcados por la violencia. Si la idea de crisis se invoca para nombrar un estado de excepción, aquí el estado de excepción es la regla ${ }^{37}$.

El alcance del Estado de Sitio fue tan evidente y trajo tantas consecuencias al país en torno al manejo de concepciones como "orden público", "enemigo interno", "seguridad nacional" y demás etiquetas referidas a lo largo del texto, que autores como Díaz-Callejas ${ }^{38}$ advierten que este se convirtió en herramienta de dominación y represión, convocado algunas veces por motivos legítimos y otras por causas ilegítimas. Francisco Leal señala, que el Estado de Sitio sirvió:

[...] más para reprimir los movimientos populares que para combatir la violencia armada. Así, el Estado de derecho en Colombia, fue abolido de facto, pues, hasta la promulgación de la Constitución de 1991, Colombia vivió casi siempre bajo las condiciones del Artículo 121 de la Carta de $1886^{39}$.

\footnotetext{
${ }^{35}$ Con relación a la desarticulada elaboración de planes de seguridad, especialmente después de la década de 1970, LEAL BUITRAGO, Francisco, La Seguridad de la Inseguridad. Colombia 1958-2005, Bogotá, Editorial Planeta; ROMERO HERRERA, Joaquín, Evolución institucional de la política de seguridad y defensa, su creación, regulación y ejecución, Bogotá, Universidad de los Andes, 2006.

${ }^{36}$ Ver un estudio sobre la aplicación e instrumentalización de la Doctrina de Seguridad Nacional a través del Estatuto de Seguridad aplicado en JIMÉNEZ, Catalina, Op cit., pp. 158-174.

${ }^{37}$ OCHOA GAUTIER, Ana María, "Sobre el estado de excepción como cotidianidad: cultura y violencia en Colombia”, en CLACSO, (Ed.), La cultura en las crisis latinoamericanas, Buenos Aires, CLACSO, Consejo Latinoamericano de Ciencias Sociales Editorial, 2004, p. 17.

${ }^{38}$ DIAZ-CALLEJAS, Apolinar, "El Estado de sitio ante la Constituyente colombiana", en Nueva Sociedad, No. 112, 1991, pp. 70-71.

${ }^{39}$ LEAL BUITRAGO, Francisco, La Seguridad de la ..., Op. cit., p. 69.
} 
El Cuadro 1 ofrece los decretos legislativos expedidos con motivo de las declaraciones de turbación del orden público y la instauración de Estados de Sitio desde 1965 hasta 1982. Podemos señalar que durante diecisiete años, solo en cuatro de ellos hubo un plano de normalidad, en contraste con trece años de preeminencia autoritaria o "estado de guerra". Es preciso tener en cuenta que el espacio más extenso en excepcionalidad comprende el lapso de 1976 a 1982, lo que permite inferir que desde 1965 el gobierno de Julio César Turbay Ayala fue el único período presidencial que inició y finiquitó su mandato bajo la figura del Estado de Sitio.

Cuadro 1. Declaraciones de Estado de Sitio, 1965 y 1982

\begin{tabular}{|l|l|}
\hline Decreto-Legislativo No. & \multicolumn{1}{|c|}{ Objeto } \\
\hline $\begin{array}{l}1288, \\
21 \text { de mayo de } 1965\end{array}$ & $\begin{array}{l}\text { Se declara turbado el orden público y en Estado de Sitio todo el } \\
\text { país. }\end{array}$ \\
\hline $\begin{array}{l}3070 \\
16 \text { de enero de } 1968\end{array}$ & $\begin{array}{l}\text { Se declara restablecido el orden público y se levanta el Estado de } \\
\text { Sitio en todo el territorio de la República. }\end{array}$ \\
\hline $\begin{array}{l}590 \\
29 \text { de abril de } 1969\end{array}$ & $\begin{array}{l}\text { Se declara turbado el orden público y en Estado de Sitio todo el } \\
\text { territorio nacional. }\end{array}$ \\
\hline $\begin{array}{l}738 \\
27 \text { de mayo de } 1970\end{array}$ & $\begin{array}{l}\text { Se declara restablecido el orden público y se levanta el estado } \\
\text { de sitio. }\end{array}$ \\
\hline $\begin{array}{l}250 \\
3 \text { de marzo de } 1971\end{array}$ & $\begin{array}{l}\text { Se declara turbado el orden público y en estado de sitio todo el } \\
\text { territorio de la República. }\end{array}$ \\
\hline $\begin{array}{l}2725 \\
20 \text { de enero de } 1973\end{array}$ & $\begin{array}{l}\text { Se declara restablecido el orden público y se levanta el estado } \\
\text { de sitio. }\end{array}$ \\
\hline $\begin{array}{l}1136 \\
12 \text { de julio de } 1975\end{array}$ & $\begin{array}{l}\text { Se declara turbado el orden público y en estado de sitio los } \\
\text { Departamentos de Antioquia, Atlántico y Valle del Cauca. }\end{array}$ \\
\hline $\begin{array}{l}1249 \\
21 \text { de julio de } 1975\end{array}$ & $\begin{array}{l}\text { Por el cual se extienden a todo el territorio nacional las } \\
\text { declaraciones de turbación del orden público y de estado de sitio. }\end{array}$ \\
\hline $\begin{array}{l}1263 \\
19 \text { de julio de } 1976\end{array}$ & $\begin{array}{l}\text { Se declara restablecido el orden público y se levanta el estado de } \\
\text { sitio en todo el territorio nacional. }\end{array}$ \\
\hline $\begin{array}{l}2131 \\
27 \text { de octubre de } 1976\end{array}$ & $\begin{array}{l}\text { Se declara turbado el orden público y el estado de sitio todo el } \\
\text { territorio nacional. }\end{array}$ \\
\hline $\begin{array}{l}1674 \\
5 \text { de julio de } 1982\end{array}$ & $\begin{array}{l}\text { Se declara restablecido el orden público y se levanta el estado de } \\
\text { sitio en todo el territorio nacional. }\end{array}$ \\
\hline
\end{tabular}

Fuente: Cámara de Representantes de Colombia, "Decretos con fuerza de ley: por orden cronológico: 1968 a 1979”, ftp://ftp.camara.gov.co/camara/basedoc/arbol/5101.html; 1980 a 1991, ftp://ftp.camara.gov. co/camara/basedoc/arbol/4213.html.

En medio de ese turbulento escenario, los estamentos político y militar cristalizaron directrices que permitieron crear el documento que más apropió los lineamientos estadounidenses respecto de seguridad nacional, El Estatuto de Seguridad colombiano. 


\section{Aplicación del discurso sobre seguridad, 1978-1982}

Colombia se presenta como uno de los pocos países en los que se sostuvieron las instituciones democráticas entre 1960 y 1990. Por otra parte, desde una postura constitucional se reforzó e intensificó el ejercicio de un Poder Ejecutivo cada vez más autoritario, en consonancia con las políticas en el subcontinente. A partir de ello, surgen los lineamientos que caracterizaron la administración de Turbay Ayala, a la cual se le asignó el rótulo de ser una de las más represivas durante la segunda mitad del siglo XX en Colombia.

El heredado manto de autoritarismo identificado como un régimen de excepción, en el cual el presidente se consideraba designado para salvaguardar el orden público y rescatar la moral de la nación, se conjugó con un factor circunstancial que obligó a Turbay Ayala a gobernar en medio de la excepcionalidad, una causa por cual se autodefinió como un abnegado defensor: "Yo, como guardián del orden público, [...] tengo que correr todos los riesgos y enfrentar todos los retos en el cumplimiento severo y firme de mis obligaciones de gobernante"40. Esta posición soportó todas las medidas adoptadas para la protección de la honra, vida y bienes de los ciudadanos, aun cuando fuese necesario recurrir a medios que atentaran contra la colectividad misma. En una entrevista que concedió en 1979, se denota textualmente la actitud del presidente, respecto de cómo se comportaría en el cuatrienio:

Señor Presidente, usted está aplicando mano fuerte al terrorismo en Colombia. ¿No es al mismo tiempo riesgoso?

Pues sí: el ejercicio del gobierno tiene riesgos, pero el mayor de éstos sería permitirle a los terroristas que ellos obraran con la tolerancia del gobierno. El gobierno tiene que asumir sus responsabilidades sin vacilar en las consecuencias que a sus integrantes pueda acarrearles el cumplimiento de sus deberes. Cuando uno jura cumplir la Constitución y las leyes, debe cumplirlas cualquiera sea el precio de esa misión ${ }^{41}$.

La respuesta del presidente expone una intención, que incluso cuando intenta justificarla en la amenaza terrorista, permite observar el interés manifiesto por el "empleo de la coacción y la restricción de las libertades públicas, para enfrentar la crisis política y económica con la que se cerraba el régimen del Frente Nacional y se inauguraba una nueva época en la vida política colombiana" ${ }^{\prime 2}$. Este proceder por parte de los actores políticos colombianos permite analizar cómo el discurso político es pieza fundamental en la reproducción de la violencia, pues el uso del lenguaje no configura un acto informativo desinteresado, sino todo un proceso de posicionamiento cognitivo de identidad entre el sujeto y su relación con el entorno. Precisamente a través de

\footnotetext{
${ }^{40}$ República de Colombia, Secretaría de Información y Prensa de la República (en adelante RC, SIPR) 1982 b, p. 240.

${ }^{41}$ RC, SIPR 1980, p. 422.

${ }^{42}$ PARADA SANABRIA, Pompeyo José, "El proceso político colombiano durante el gobierno de Julio César Turbay Ayala", en Eleuthera, No. 7, 2012, p. 138.
} 
dicho proceso, “[...] se ha inducido a los individuos a actuar de forma intolerante frente a quienes representan la diferencia, [...] logrando sugerir en amplios sectores sociales, el imaginario de que lo opuesto es lo que genera desorden y violencia" ${ }^{43}$. De ahí que su posición reproduzca un imaginario de "riesgo" para la nación, que reafirma el preponderante papel del Ejecutivo para salvaguardar la integridad nacional. Esto se traduce en la búsqueda de legitimación frente a la ejecución de los medios más expeditos, que por su naturaleza represiva, concuerdan con la última expresión planteada: "cualquiera sea el precio de esa misión".

Por consiguiente, el papel de la institución militar se vigorizó; puesto que, como lo advierte Olarte, "el Presidente no tenía un proyecto político definido y menos en materias militares. Optó por dejar el campo libre a las iniciativas provenientes del Ministerio de Defensa, lo que además era avalado por la tradición del Frente Nacional"44. El presidente buscó legitimar el expansivo papel de las Fuerzas Armadas como institución central, para el restablecimiento del orden y la moral pública. Construyó nexos argumentales que trascendieron los rasgos característicos de esta institución y la situaron en un plano privilegiado con responsabilidades que no eran de su competencia:

Hasta hace poco, la participación de las Fuerzas Armadas en el mantenimiento del orden interno era relativamente escasa. Hoy, cuando son menos frecuentes que en el pasado los estados de guerra entre naciones, es cada vez más sustancial su papel en la defensa de las instituciones políticas [...].

Pueden darse, naturalmente, casos extremos en los que, ante un ostensible vacío político que necesariamente conduce hacia la anarquía generalizada, las Fuerzas Armadas se vean precisadas a ejercer el poder para reestablecer el imperio de la autoridad ${ }^{45}$.

En el primer párrafo se brinda un argumento de aplicabilidad, es decir, frente a la reducción de conflictos bélicos internacionales, el papel de las fuerzas armadas era poco relevante, razón por la cual era apropiado proveer espacios para el actuar militar en el plano nacional. Esta plataforma ideológica fue el sustento de todo el movimiento dictatorial de la época, que facultó a las instituciones militares de un rol activo en temas de carácter civil, incluso se militarizó a la institución policial. En el segundo párrafo, por tanto, se expresa la concreción del contexto de la época que, aun cuando no llegó a tal punto, contemplaba la posibilidad de que las Fuerzas Armadas accedieran de facto al poder, en caso de un vacío político ostensible.

Las competencias adquiridas por las Fuerzas Armadas estuvieron mediadas por un factor de modernización, donde las instrucciones recibidas de Estados Unidos justificaban el papel cada vez más activo de la institución castrense en la sociedad

\footnotetext{
${ }_{43}$ PUERTA HENAO, Catalina María, "Discurso político y violencia en Colombia”, en Estudios de Derecho, Vol. 65, No. 145, 2008, p. 217.

${ }^{44}$ OLARTE NIÑO, Tamanai, Op cit., p. 22.

${ }^{45}$ RC, SIPR 1981, pp. 219-220.
} 
civil. Lo corroboran las palabras dadas por el Primer Mandatario en el acto de clausura de un curso sobre administración para oficiales de la Escuela Superior de Guerra: “[...] los conocimientos académicos, técnicos y científicos, adquiridos en esta escuela, garantizan la idoneidad con que pueden desempeñar los altísimos cargos a que están llamados [los militares]"46; de modo que la educación en las Fuerzas Armadas se convirtiera en garantía para tenerlas presentes en "las dimensiones de la administración, de la economía, del saber humano en distintos aspectos"47.

El Primer Mandatario en su discurso de posesión solicitó a la sociedad -respecto de las Fuerzas Armadas-, un papel comprensivo, solidario y activo en la lucha contra aquellos que promovían el imperio del crimen y querían ver a Colombia regida por sistemas que no eran los de la democracia ${ }^{48}$. El resultado final, una institucionalidad castrense que se autoproclamó orientadora de los intereses nacionales y capturó el rol estatal para el diseño y la implementación de las medidas de seguridad, canalizadas a través de la representación político-militar del presidente de la República. Como lo señala Leal, “[...] por eso, para poder [los militares] cumplir cabalmente con la función prioritaria de seguridad, el 'poder nacional' debe acumular en manos del gobierno todos los recursos existentes (políticos, económicos, sociales, psicológicos y militares)" 49 .

Bajo la configuración de las relaciones Presidente y Fuerzas Armadas, es permisible señalar que las medidas de seguridad adoptadas en el período de gobierno 1978-1982 fueron producto de diversos lineamientos y presiones instauradas por las instituciones militares, resultado de la influencia de la Doctrina de Seguridad Nacional. Al tiempo que la improvisación gubernamental facilitó la entronización de las instituciones castrenses, lo cual se reflejó en su preocupación por acceder a la estructura del Estado.

Sin embargo, al acercarse a la noción seguridad, esta se presenta como un elemento difuso y de gran complejidad, pues su uso, más implícito que explícito, estuvo mediado por una instrumentalización elástica y ambigua, cooptada por diversos intereses de la élite militar. Como lo plantea Nieto, siguiendo a Studer:

En adición a su clásica misión de defensa interna, el ejército combate los insurgentes dentro del territorio colombiano, se ocupa en parte del desarrollo económico, de la defensa civil, de los programas de socialización y educación: el Ejército ha llegado a ser el brazo indispensable del gobierno ${ }^{50}$.

\footnotetext{
${ }^{46}$ RC, SIPR 1981, p. 164.

${ }^{47}$ Ibid.

${ }^{48}$ RC, SIPR 1980, p. 29.

${ }^{49}$ LEAL BUITRAGO, Francisco, "Surgimiento, Auge...", Op. cit., p. 39.

${ }^{50}$ NIETO ORTIZ, Pablo Andrés, ¿Subordinación o autonomía? El ejército colombiano, su relación política con el gobierno civil y su configuración en la violencia, 1953-1990, Informe final del concurso: El papel de las fuerzas armadas en América Latina y el Caribe, Programa Regional de Becas CLACSO, 2004, pp. 2324, siguiendo a STUDER, Robert William, The Colombian army: political aspects of its role, Los Ángeles, Estados Unidos, University of Southern California, 1975.
} 


\title{
Del Estado de Sitio y el discurso presidencial
}

Al papel que se endilga el Jefe de Estado y por ende las Fuerzas Armadas, frente a la tutela de los destinos de la nación, se adiciona una segunda intencionalidad: procurar el retorno a la normalidad constitucional. Durante su mandato se observa que el no cumplimiento de su proyección siempre estuvo condicionada por el contexto nacional e internacional: "[...] el estado de sitio yo no lo impuse, sino que lo heredé, pero encontré que no estaba en condiciones de renunciar a él", advierte Turbay Ayala ${ }^{51}$. La anterior pieza discursiva es clave, pues resalta cierta posición de discrepancia del presidente con relación al uso del estado de excepción. No obstante, dicha presunción se tornó en estrategia demagógica para justificar acciones de gobierno. Observemos:

\begin{abstract}
Ningún gobierno democrático es partidario de gobernar por procedimientos de excepción. Yo preferiría no tener que hacer uso del estado de sitio, ni haber tenido que expedir el Estatuto de Seguridad. Ambas medidas se han tomado contra el criterio del gobierno y por fuerza misma de las circunstancias. La verdad es que dentro del pleno estado de normalidad, ni este gobierno ni el de mis antecesores, han logrado aclimatar la paz. Uno y otros tuvieron que hacer uso de las disposiciones del Artículo 121 de la carta ${ }^{52}$.
\end{abstract}

Turbay Ayala intenta reflejar cómo fue sujeto y objeto de circunstancias y coyunturas que determinaron la necesidad del uso de las medidas de excepción. A pesar de esto, se observa que en su discurso se hizo frecuente el uso de algunos "temas comodín" -asuntos que cambiaron de matiz de modo deliberado y según la coyuntura-. Tales temas tenían por objetivo orientar la opinión pública hacia puntos estratégicos respecto de la agenda de gobierno.

En las alocuciones del presidente Turbay Ayala se identifica al Estado de Sitio como el "comodín" más reiterativo, vinculado al objetivo de legitimar múltiples acciones del gobierno, aun cuando el presidente reconociera que su uso había afectado a la República ${ }^{53}$. De ahí que en las intervenciones oficiales se planteara directa e indirectamente como algo indeseado y perjudicial para el sistema democrático.

Analicemos tres fragmentos a modo de ilustración de cómo se utilizó discursivamente la noción Estado de Sitio en busca de cánones de legitimación:

1. Yo no lo decreté [el estado de sitio], lo encontré cuando llegué al gobierno y lo he utilizado al servicio de la paz de los colombianos, y mientras la paz lo requiera, lo mantendré. Pero, desde luego, también quiero decir que deseo que muy pronto podamos nosotros prescindir de las vías de excepción; que podamos llegar a la plena normalidad constitucional, para la cual dio un paso fundamental la reforma de las instituciones, la reforma a la justicia [...]. Esto es importante; si no se establecen mecanismos de esta naturaleza, no se puede hacer el tránsito a la plena normalidad ${ }^{54}$.

\footnotetext{
${ }^{51}$ RC, SIPR 1981, p. 396.

${ }^{52}$ RC, SIPR 1980, p. 213.

${ }^{53}$ RC, SIPR 1982a, p. 324.

${ }^{54}$ RC, SIPR 1981, p. 309.
} 
En primera instancia, se esgrime una alusión directa al Estado de Sitio: preservar el valor de la paz. Sin embargo, cuando en lo textual pareciera ser lógica y consecuente esa relación, interesa observar más allá y centrar el punto de análisis en la relación reforma - retorno a la normalidad. Allí se encuentra el uso del Estado de Sitio como “comodín”. Debido a que la paz está afectada por diferentes factores y actores, y a su vez es el principal objetivo por parte del gobierno, se torna necesario efectuar varias reformas a las instituciones estatales, haciendo especial énfasis en el sector judicial. En últimas, los ajustes legislativos se convirtieron en el referente para el cese del estado de excepción y el retorno a la normalidad. Aun así, se lograron reformas, por ejemplo, el Acto-Legislativo No. 01 de 1979, por medio del cual se reformó la Constitución Nacional - disposición declarada inexequible en su totalidad por parte de la Corte Suprema de Justicia (Sala Plena) el 3 de noviembre de 1981-55; y la aprobación de normativas como el Decreto-Ley 100 de 1980, por el cual se expidió un nuevo Código Penal -el presidente se sirvió de la Ley 5a de 1979, que lo revistió de facultades extraordinarias por el término de un año para expedir dicho código-. Pese a esto, esas medidas nunca se tradujeron en la derogación de la excepcionalidad de estado. Se observa entonces, cómo el despliegue discursivo en favor del desmonte del Estado de Sitio funcionó de bastión para orientar la opinión pública hacia un escenario puntual, so pretexto de justificar las reformas e iniciativas legislativas presentadas.

Detengámonos en la segunda forma con que se utiliza la noción Estado de Sitio, esta vez en torno a los actores desestabilizadores que, además de ser diversos, están alejados del contexto institucional planteado con anterioridad, aunque condicionados por este. Es decir, las múltiples reformas e iniciativas legislativas gubernamentales terminaron siendo vehículos represivos, que endurecieron las medidas en torno a quienes afectaban o pretendían afectar el orden público ${ }^{56}$. En esa medida, el núcleo de la interpretación se encuentra en la relación subversión - retorno a la normalidad:

2. El ejecutivo ha reiterado su decisión de avanzar hacia la normalidad. Quienes todavía no han hablado el mismo lenguaje son aquellos que persiguen opuestos objetivos y utilizan las más variadas armas, incluyendo las del estímulo y justificación de las actividades terroristas que les brindan con generosidad algunos organismos y no pocos individuos ${ }^{57}$.

\footnotetext{
${ }^{55}$ En torno al papel del control judicial a las reformas constitucionales, ver: CAJAS SARRIA, Mario Alberto y LÓPEZ MEDINA, Diego Eduardo, El control judicial a la reforma constitucional: Colombia, 1910-2007, Cali, Universidad Icesi, 2011; CAJAS SARRIA, Mario Alberto, La Corte Suprema controla la reforma constitucional (1978-1990), Cali, Universidad Icesi, 2011.

${ }^{56}$ En este escenario confluyen las medidas adoptadas bajo la figura del Estado de Sitio, la utilización de las disposiciones constitucionales, tales como: el Artículo 28 ( permitía proceder, después de consultar al Consejo de Estado y por decisión del consejo de ministros, a la detención durante diez días de toda persona sospechosa de querer alterar el orden público), el despliegue del Estatuto de Seguridad (desde el cual se hizo entrega, por ejemplo, de amplias facultades a los militares para el juzgamiento de civiles involucrados en actividades guerrilleras) y el incremento en las penas para el secuestro y la modificación de la tipología penal de la sedición, se hizo más amplia, entre otras disposiciones. Cf. OLARTE NIÑO, Tamanai, $O p$ cit., pp. 21-22. Entre 1979 y 1980 fueron juzgados 472 a los cuales se les acuso de pertenecer a movimientos subversivos según lo señala JIMÉNEZ, Catalina, Op cit., p. 168.
}

${ }^{57}$ RC, SIPR 1981, p. 341. 
El anterior texto parte de un ejercicio de mímesis en el que hay una réplica discursiva del contexto internacional de la Guerra Fría en la esfera nacional, a partir de la lucha contra los actores que atentan la estabilidad democrática (rebeldes, comunistas, subversivos, terroristas, guerrilleros, etcétera $)^{58}$. Este período, en el cual proliferó el uso de rótulos como "enemigo interno" y la permanente ideología anticomunista, derivó en un conjunto de representaciones dentro de la lógica militar amigo-enemigo. Desde esta perspectiva, el discurso de Turbay Ayala reproduce el constructo caracterizador de la subversión: “[...] yo combato la subversión, porque la subversión está integrada por fuerzas impías, paganas, ateas que no creen en ningún Dios sino en el poder de la barbarie y de la fuerza bruta" ${ }^{59}$. Se trata, básicamente, de la clara distinción, por un lado, de un mundo occidental orientado a la salvaguarda de los principios democráticos, el cristianismo y la civilidad; por otro, la Unión de Repúblicas Socialistas Soviéticas (URSS) que representaba la expresión más clara del comunismo, el ateísmo, el totalitarismo y, sobre todo, de su actuar bárbaro. Sin duda, como lo manifiesta Leal, la DSN fue trascendental en este punto, pues a partir de los años sesenta, permitió "enfocar un solo enemigo, estigmatizarlo y diferenciado de los demás. Pero, sobre todo, le proporcionó razón de ser institucional al calificativo de enemigo para cualquier persona o grupo sospechoso de ser comunista" ${ }^{\circ 0}$.

La influencia internacional de la DSN y los rezagos ideológicos persistían a finales de la década 1970, pero con los sucesos centroamericanos del triunfo de la Revolución Popular Sandinista en Nicaragua (1979-1990) y el intenso conflicto bélico de la guerra civil en El Salvador (1980-1992), se reactivaron en gran medida al amparo de la administración del presidente estadounidense Ronald Reagan (1981-1989). El punto de discordia se tejería nuevamente alrededor de La Habana y los países socialistas de Europa del Este. El paroxismo resurgió, presentando en el discurso regional de una tensa y peligrosa imagen de los recientes acontecimientos, sobre todo en el caso colombiano por su proximidad territorial y la influencia que recaería en diferentes agrupaciones guerrilleras. La tensión se expresa en palabras del mandatario del siguiente modo: "La América y concretamente la cuenca del Caribe está hoy amenazada por la influencia de fuerzas extracontinentales ajenas por entero a la ideología bolivariana, a la ideología democrática" ${ }^{\prime 61}$. El triunfo de fuerzas foráneas auguraba un nefasto porvenir para Colombia, mediado por el " [...] régimen del terror, el imperio de la barbarie, la fratricida lucha clasista, la abolición de las libertades y el desbarajuste administrativo" 62 .

\footnotetext{
${ }^{58}$ Iván Orozco Abad expone una visión desde el tratamiento jurídico a las diversas connotaciones con las cuales se ha identificado a los actores opositores a la organización del Estado, atendiendo que los cambios en dichas connotaciones, han trazado una historia jurídica propia, con relación al delito político en Colombia. Ver: OROZCO ABAD, Iván, Combatientes, rebeldes y terroristas. Guerra y derecho en Colombia, Bogotá, Instituto de Estudios Políticos y Relaciones Internacional-Universidad Nacional de Colombia-Temis, 1992. ${ }^{59}$ RC, SIPR 1982b, p. 155.

${ }^{60}$ LEAL BUITRAGO, Francisco, La Seguridad de la Inseguridad. Colombia 1958-2005, Bogotá, Editorial Planeta, 2006, p. 53.

${ }^{61}$ RC, SIPR 1982b, p. 9.

${ }^{62}$ RC, SIPR 1982a, p. 448.
} 
Al considerar los acontecimientos, actores y representaciones anteriormente expuestos, el discurso turbayista condiciona su disposición y posibilidad de retornar a la normalidad constitucional, a las actitudes asumidas por parte de la subversión. En esa lógica, el Estado de Sitio se justifica y permite orientar la cognición social a la necesidad de sostener la excepcionalidad como instrumento para encarar el efervescente contexto nacional e internacional.

Hasta aquí hemos presentado dos formas mediante las cuales se utilizó el ideal del desmonte del Estado de Sitio como estrategia para direccionar la opinión pública hacia los intereses del gobierno. Empero, ambos fragmentos denotan una amplitud de opciones a tener en cuenta, ya que en el primer caso las reformas solicitadas eran de distinta índole y, en el segundo, las problemáticas que derivaban de la subversión también eran múltiples. En el siguiente fragmento, en contraste con los dos fragmentos anteriores, se podrá observar un condicionamiento puntual, mediante el cual se promocionó la idea del desmonte del estado de sitio a partir de una acción concreta:

1. Séame permitido reafirmar la opinión de que si se aprueba el proyecto de amnistía originario de la Cámara de Representantes y a él se acogen los alzados en armas, el gobierno no vacilará en dar los pasos inmediatos para facilitar el retorno a la plena normalidad constitucional ${ }^{63}$.

La falta de un proyecto político claro y consistente durante la presidencia de Turbay Ayala, reverberó en un plan de gobierno ineficaz, que dejó grandes deudas en materia de Derechos Humanos y gobernabilidad ${ }^{64}$. Comprender entonces lo expuesto en el fragmento anterior, requiere de una contextualización más amplia que posibilite un mejor análisis.

El 8 de agosto de 1978 se posiciona Julio César Turbay Ayala como presidente de la República, y un mes más tarde, el 6 de septiembre expide el Decreto 1923, “[...] por el cual se dictan normas para la protección de la vida, honra y bienes de las personas y se garantiza la seguridad de los asociados"; decreto conocido como el Estatuto de Seguridad. Estas medidas constituyen la política más controversial del gobierno nacional. Ramírez lo plantea del siguiente modo:

[...] la recopilación metódica de decretos dictados por diferentes gobiernos en América Latina y en Colombia, en función del estado de sitio [...] es la puesta en marcha de manera concreta de la doctrina de la seguridad nacional y la democracia restringida propugnada por el gobierno norteamericano para el mantenimiento de las condiciones estructurales de la dependencia, sin tener que recurrir a la instauración de regímenes militares, sino a través del estado de sitio permanente, la militarización de la justicia, la censura de los medios

\footnotetext{
${ }^{63}$ Ibid

${ }^{64}$ Jiménez señala que después del robo de armas en el Cantón Norte fueron capturadas 936 personas y con ello la tortura física y psíquica de los detenidos. Así mismo aumenta la cifra de refugiados políticos, la desaparición forzada, por consiguiente el reporte de desaparecidos, y la violación a los procedimientos legales de detención. La desaparición forzada aumentó especialmente en las zonas rurales del Caquetá, Meta, sur del Huila y la región del Magdalena Medio. JIMÉNEZ, Catalina, Op cit., pp. 167-169.
} 
de comunicación, la intervención y ocupación militar de las universidades públicas, la sujeción de la administración de justicia al ejecutivo, etcétera ${ }^{65}$.

Diversos sectores sociales eran conscientes de lo que representaba la promulgación del Decreto. El respaldo al Ejecutivo, tras haberse declarado exequible su iniciativa por parte de la Corte Suprema de Justicia ${ }^{66}$, le aseguró al presidente el acceso a los mecanismos de la fuerza, como política para combatir los problemas de desorden público; de igual forma, hacer algunas afirmaciones discursivas en las que reconocía la presencia de movimientos subversivos. El énfasis estuvo en sostener que dichos grupos no tenían "poder suficiente para derrumbar las instituciones democráticas y sustituirlas por el imperio del motín" ${ }^{67}$; con lo cual se conectó y justificó su lucha contra la subversión. Su línea argumental llegaría a sostener "[...] [haber] logrado reducir casi a proporciones insignificantes la subversión; hemos quitado su peligrosidad, pero necesitamos que no desmayen los ciudadanos en la gran empresa de la paz"68.

Esa postura se fue desdibujando al considerar las complejas dinámicas del contexto internacional ya referidas. En ese sentido, se pasó de tratar a la subversión como un actor limitado y sin posibilidad de acceder al poder legítimamente constituido, a inicios del gobierno de Turbay, para referenciarlo luego como enemigo potencial a quien había que responder con todo el ahínco necesario. De hecho, en ocasiones el discurso se presentó en un tono alarmante: "He venido preocupado, como jefe del Estado, porque al amparo de la anarquía política pueda prosperar el movimiento subversivo que acecha y está pronto a darle un zarpazo al estado en la medida en que nos descuidemos" ${ }^{69}$. Si a lo anterior se suman los acontecimientos del robo de las cinco mil armas del Cantón Norte (Bogotá) el 1 de enero de 1979 y la toma a la Embajada de República Dominicana el 27 de febrero de 1980 por parte de la guerrilla M-19, se hace evidente la agudización del Estado de Sitio y la necesidad de nuevos marcos normativos que dieran más facultades a las Fuerzas Armadas en temas de seguridad e integridad nacional ${ }^{70}$.

\footnotetext{
${ }^{65}$ RAMÍREZ, Luis Jairo, "Lo que va del Estatuto de Seguridad a la Política de Seguridad Democrática", en Boletín Actualidad Colombiana, No. 416, 2005, p. 1.

${ }^{66}$ El 30 de octubre de 1978, mediante el Acta No. 30, la Sala Plena de la Corte Suprema de Justicia declaró exequible la mayoría de las disposiciones del Decreto 1923, aduciendo entre otras cosas: "El Decreto 1923 no ha roto la estructura orgánica del Estado. -En estado de sitio cabe una drasticidad punitiva mayor que la ordinaria y una aceleración de los procedimientos aunque ello implique modificación transitoria de los códigos. -Prensa. No es libre en tiempo de anormalidad. -Huelga. Lo que garantiza el Artículo 18 de la Carta es el ejercicio legítimo de dicho derecho, más no la paralización de los servicios públicos, o el cese injustificado en las demás actividades, o fuera de la oportunidad legal, o con finalidades distintas a las estrictamente laborales". Ver sentencia completa en: ftp://ftp.camara.gov.co/camara/basedoc/csj_nf/ sp/1978/csj_sp_d1923_78_30-10_1978.html\#1.

${ }^{67}$ RC, SIPR 1980, p. 239.

${ }^{68}$ RC, SIPR 1981, p. 309.

${ }^{69}$ RC, SIPR 1982b, p. 258.

${ }^{70}$ En el informe de Amnistía Internacional de 1980 se cuantifica la realidad del siguiente modo: " 1.500 Consejos Verbales de Guerra con 3.800 condenados en 8 años [...] 35 centros y 25 formas de tortura; 9 zonas campesinas militarizadas; 48 indígenas del Comité Regional Indígena del Cauca (CRIC), tres sindicalistas y un médico, asesinados; un periodista desaparecido; 68.000 detenidos para ser investigados". Ver CORREDOR, Fernando, “Colombia: la democratización del régimen y sus obstáculos”, en Nueva Sociedad, No. 69, 1983, p. 144.
} 
A pesar de que se sostuvieron todos los mecanismos amparados en el Estatuto de Seguridad, la actitud del gobierno cambió. Esto permite interrogar por qué en un mandato caracterizado por la represión se generaron dos iniciativas de amnistía (una por parte del presidente de la República y otra por la Cámara de Representantes), así como la promoción de una Comisión de Paz encabezada por el expresidente Carlos Lleras Restrepo. Si bien hay factores del contexto internacional y nacional que pudieron incidir, como lo advierte Jiménez ${ }^{71}$, la respuesta se encuentra en el trasfondo, pues las garantías para alcanzar el "objetivo de apaciguar la paz" nunca llegaron a ser efectivas, contrario a ello, el rechazo de los grupos subversivos a las propuestas del gobierno llevó al endurecimiento de las medidas represivas. En términos generales, las estrategias para promover la desmovilización de los alzados en armas, terminaron siendo un nuevo intento de legitimización a las acciones opresivas:

Quiero garantizar a todos ustedes que haremos el máximo esfuerzo posible, utilizando los procedimientos de la persuasión y de la inteligencia, inicialmente para tratar de aclimatar la paz entre la familia colombiana y luego, si ellos nos fallan, hacer uso de los recursos que la Constitución y la ley ponen al alcance del gobierno, para no permitir que se subvierta el orden jurídico y pueda, en procedimiento de hecho, dar alguien un zarpazo sobre el Estado ${ }^{72}$.

El anterior fragmento constituye un antilógico. Como se expuso, la primera medida adoptada por el gobierno fue el Estatuto de Seguridad, conjunto de medidas que agudizó los mecanismos legales del Estado. Luego, con los sucesos ocurridos entre 1979 y 1980, se esgrimieron propuestas para un acercamiento a la paz. No es preciso plantear entonces que se buscó la paz haciendo uso en primera instancia de la persuasión, pues efectivamente es claro que se irrumpió con fuerza (desmedida) y solo en los últimos meses de gobierno se estructuraron y avalaron algunas propuestas de paz, lo que significa que al no ser eficaces los mecanismos disuasivos y encontrar en los grupos subversivos una "posición hostil y desinteresada", se mantuvo el Estado de Sitio y toda su implicaciones.

Como se observa, las tres instauraciones discursivas tienen como objeto en común, pretender el desmonte del Estado de Sitio a partir de ciertas medidas impulsadas por el gobierno. Por supuesto el no cumplimiento a cabalidad de dichas propuestas, ameritó la sostenibilidad de la excepcionalidad, con lo cual se garantizaba una influencia directa del Ejecutivo y las Fuerzas Armadas en el diseño y la ejecución de las estrategias de seguridad.

\footnotetext{
71 Catalina Jiménez señala como factores internacionales: los informes y reportes periodísticos internacionales, el informe de Amnistía Internacional de 1980, el Informe de la Comisión Interamericana de Derechos Humanos de 1981 y la consolidación de una agenda política internacional de la defensa y protección de los derechos humanos en cabeza del presidente norteamericano Jimmy Carter. En cuanto a los factores nacionales considera: las movilizaciones y acciones colectivas de los partidos políticos de derecha e izquierda, el papel de los abogados defensores de los presos políticos, la documentación recolectada que evidencia las irregularidades procesales y constitucionales, el primer Gran Nacional sobre Derechos Humanos, la creación de una Comisión Política encargada de crear una política institucional sobre derechos humanos, una apertura real del espacio político, la defensa del orden público y, finalmente, la acción del poder legislativo y de otras instituciones estatales. JIMÉNEZ, Catalina, Op cit., pp. 169-171.

${ }^{72}$ RC, SIPR 1982a, p. 498.
} 


\section{Representaciones discursivas sobre seguridad y paz}

Luego de establecer varios puntos estratégicos de cómo el discurso se conjugó en una relación simbiótica con el contexto y la ideología circulante en el escenario internacional, además de analizar las formas en que todo ello repercutió en las dinámicas nacionales, es pertinente identificar las representaciones más puntuales en torno al concepto seguridad, que de antemano supone ambigüedades, confusiones y traslapamientos, a su vez de términos como paz y justicia social. El análisis parte de la idea de que los tres términos son utilizados ambiguamente según la conveniencia semántica, sin derivar en una precisión terminológica, lo cual refleja el interés de posicionar o reservar algunos temas-problema de gobierno.

A partir de la teoría política moderna -desde la cual se analizan los elementos fundantes del Estado-Nación- analizamos una referencia explícita al término seguridad, evidenciada en el acto de conmemoración de los 25 años de fundación del Departamento Administrativo de Seguridad (DAS):

Es esta [la seguridad] la primera necesidad de los pueblos. Sin seguridad es imposible el discurrir de la vida colombiana, sin seguridad no hay cordialidad, sin seguridad se alteran todos los factores de la vida de relación en una sociedad interdependiente. Por eso este gobierno le otorga su importancia a la seguridad. Es un fenómeno complejo, no es de fácil administración: se requiere la colaboración no sólo de las autoridades sino también de la ciudadanía que muchas veces al asumir una actitud pasiva está contribuyendo por temor o con una irresponsabilidad realmente inexcusable a estimular el crimen ${ }^{73}$.

Del anterior fragmento se abstraen, al menos, dos consideraciones. Primero, tomar la seguridad como un factor desde el cual se estructura la sociedad, es decir, como el complejo pilar fundacional sin el cual no es factible que la vida prolifere en términos de la modernidad política. Y, segundo, resaltar la concepción amigo-enemigo, donde no hay actores neutrales, sino solo dos posibilidades (por acción u omisión): la primera, una ciudadanía que estimula las acciones de los grupos subversivos; y, la segunda, un pueblo activo y colaborador con las Fuerzas Armadas, en contra del enemigo común.

La claridad presentada en la anterior pieza discursiva respecto de la importancia de la seguridad como garantía de los intereses nacionales, se verá acompañada de otra noción, el valor de la paz:

Es la paz la infraestructura del progreso; sin paz no puede realizarse la grande empresa del desarrollo, sin paz en ningún hogar existiría tranquilidad, no se podrá disfrutar de la existencia porque estaremos en todo momento bajo el temor de que uno de nuestros compatriotas, humilde o de alta posición haya podido ser víctima del terrorismo, de todos estos métodos siniestros que está produciendo la subversión para el logro de sus fines proditorios ${ }^{74}$.

\footnotetext{
${ }^{73}$ RC, SIPR 1980, p. 136.

${ }^{74}$ RC, SIPR 1982b, p. 80.
} 
Seguridad y paz se traslapan en una amalgama de significados sin una diferenciación clara para la utilización de uno u otro término; incluso, en algunos apartes, se adoptan ambos conceptos como elementos caracterizadores de una tercera noción: "Yo creo que solo a Colombia le falta algo para ser la más próspera nación de América y es consolidar definitivamente su paz, su tranquilidad, su seguridad, que es la función esencial del Estado"75. La prosperidad se presenta como un objetivo a garantizar por parte del Estado, por ende, su logro se condiciona en la consolidación de otros elementos como son la paz, la tranquilidad y la seguridad; de tal modo que la seguridad como objetivo de estado se desnaturaliza, pues se propone como medio que posibilita más allá de la infraestructura de la paz, la empresa del desarrollo.

Es tan incierto el uso de estos términos que la bandera mediática del presidente no está planteada con relación a la utilización discursiva de conceptos como seguridad, sino más bien a diferentes acepciones de paz, aun cuando su término preferente es justicia social que incluso identificó en su momento como la acepción más ajustada de la paz:

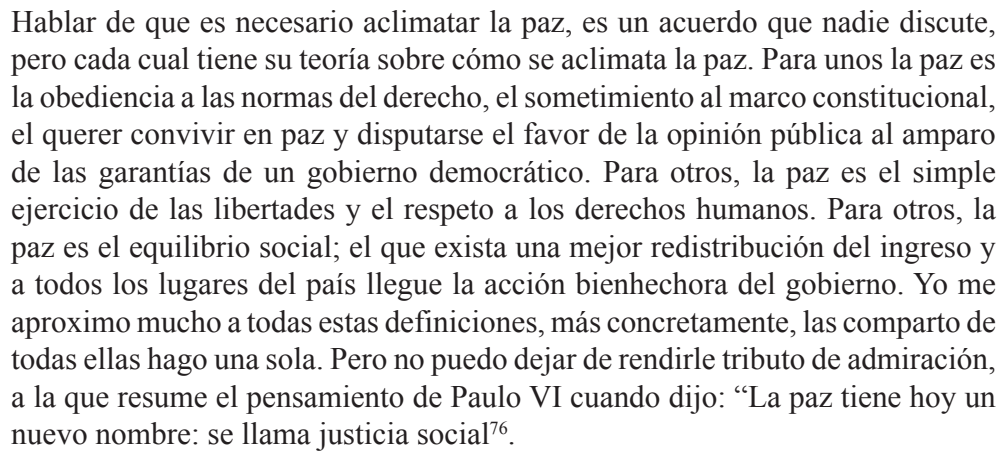

La elasticidad y la abstracción con las cuales se utiliza el concepto paz evidencian lo diverso que es el uso conceptual, pues equipara acepciones donde se presenta a la paz como un canon de obediencia a la autoridad, con otro como el simple ejercicio de libertades y el respeto a los Derechos Humanos; al finalizar, manifiesta su simpatía con la definición del Sumo Pontífice Paulo VI. Todo ello reafirma lo planteado inicialmente, que en las diferentes categorías utilizadas por el presidente Turbay, especialmente la de seguridad, es frecuente la ambigüedad.

Las representaciones que emanan de la noción seguridad están supeditadas a dos puntos que le brindan su contenido: primero, el influyente contexto internacional, que se materializó en la Doctrina de Seguridad Nacional para el cono sur; segundo, el papel de las Fuerzas Armadas en el diseño e implementación de las medidas de seguridad. Desde el primer ítem, la seguridad estuvo fundamentada en la sostenibilidad discursiva del "enemigo", que se encarnaba en los grupos guerrilleros y subversivos, las acciones terroristas y la ideología anticomunista. De ahí la

\footnotetext{
${ }^{75}$ RC, SIPR 1982b, p. 97.

${ }^{76}$ RC, SIPR 1982b, p. 118.
} 
necesidad de sostener la figura del Estado de Sitio, pues permitió mayor margen de maniobra legislativa al evitar los protocolos democráticos para la sanción de diferentes iniciativas ya referidas. Respecto del segundo punto, el acentuado contexto de violencia política en el país, después de 1948, llevó a la profesionalización de las Fuerzas Armadas, lo que en consonancia con los sistemas autoritarios de la época, permitió generar una influencia determinante de la institución castrense dentro del Estado. Así, la Seguridad de Estado y la Seguridad Nacional se conjugaron en un mismo concepto, orientado a garantizar "[...] el desarrollo integral del hombre y de las colectividades nacionales, preservándolos de interferencias o perturbaciones sustanciales de cualquier origen"77.

\section{Conclusiones}

En la relación discurso, ideología y poder, se planteó un ejercicio de análisis crítico del discurso que tuvo por objetivo establecer el contenido y las cargas de representación de la noción seguridad en el caso del presidente Julio César Turbay Ayala. A partir de la naturaleza del concepto seguridad, señalamos un uso ambiguo del término, verificado a lo largo del ejercicio hermenéutico-descriptivo, pues no solo se identificó una elasticidad comprensiva de la noción seguridad, sino también de otros términos como paz, justicia social y prosperidad, lo cual derivó en la estructuración de discursos, políticas y representaciones de diferente naturaleza.

Planteamos un recorrido histórico-contextual a partir de cinco eventos de gran trascendencia nacional: primero, la Violencia Bipartidista (1948-1958); segundo, la Modernización y Profesionalización de las Fuerzas Armadas y su papel desde el período de La Violencia; tercero, el Frente Nacional; cuarto, la segunda fase de Violencia Política en el país, desde la fundación de los grupos guerrilleros en el marco de la Guerra Fría; quinto, la figura del Estado de Sitio. Dichos sucesos permitieron entender bajo qué parámetros se relacionaron las diferentes instituciones del Estado (Presidencia, Congreso, Fuerzas Armadas, entre otras) para plantear medidas conducentes al restablecimiento del orden público. Sin duda, el agente catalizador más relevante desde lo político, lo constituyó el uso del Estado de Sitio, utilizado como "comodín", es decir, como asunto que fue cambiando deliberadamente de matiz según la conveniencia coyuntural que atravesara el país, con el fin de legitimar, en última instancia, cada una de las medidas que se fueron ejecutando.

El análisis permite observar un discurso fluctuante, motivado y condicionado por la falta de un programa de gobierno, puesto que este se diseñó en el trascurso del período mismo, al amparo de las relaciones políticas con las élites del país. No extraña entonces su filial represiva para combatir los problemas de orden público. Asimismo, su programa de reformas e iniciativas legislativas le fue garantizado los primeros años, con lo cual tuvo un margen de maniobra considerable. Sin embargo, el tenso contexto económico, el grado de deslegitimación de su mandato, así como

${ }^{77}$ LEAL BUITRAGO, Francisco, “Surgimiento, Auge...”, Op. cit., p. 53. 
la proliferación de grupos guerrilleros y su fortalecimiento, propiciaron el desmonte de varias medidas, esto puso en evidencia el equívoco del presidente en el manejo de la "política de seguridad". De ahí que se permitiera contemplar variadas propuestas desde el ejercicio democrático que, aun cuando fracasaron, fueron la antesala de lo que en próximos gobiernos sería sustancial para el desmonte de varias agrupaciones guerrilleras.

Finalmente, el elemento trasversal fue el tema de la seguridad, por vías dialógicas o por la fuerza, este se observó difuso y ambiguo, direccionado por la doctrina militar, soportado bajo los presupuestos ideológicos de la Guerra Fría y materializado particularmente en el Estatuto de Seguridad. En esa medida, la construcción de lógicas dicotómicas mediante el ejercicio de las relaciones amigo-enemigo, permitió desentrañar el conjunto de representaciones de la seguridad como factor inestable y pieza fundamental para el desarrollo del país. Aunado a lo anterior, subsistió un segundo conjunto de representaciones que sustentaron un escenario social hostil, caótico y amenazante, en el que se apeló a diversas estrategias retóricas para orientar la cognición social hacia puntos estratégicos de la agenda de gobierno. El objetivo final entonces fue la búsqueda de legitimidad, respecto de la propuesta de seguridad, que terminó siendo la implementación de una política orientada hacia el ejercicio y la reproducción de la violencia.

\section{Fuentes}

\section{Fuentes primarias}

\section{Documentación primaria impresa}

REPÚBLICA DE COLOMBIA, SECRETARÍA DE INFORMACIÓN Y PRENSA DE LA REPÚBLICA, Discursos y Mensajes del Presidente de la República Julio César Turbay Ayala, desde el comienzo de su administración, en agosto de 1978, al mes de agosto de 1979, Bogotá, Talleres Gráficos del Banco Popular, 1980.

REPÚBLICA DE COLOMBIA, SECRETARÍA DE INFORMACIÓN Y PRENSA DE LA REPÚBLICA, Discursos y Mensajes del Presidente de la República Julio César Turbay Ayala, de agosto de 1979, a agosto de 1980, Bogotá, Talleres Gráficos del Banco Popular, 1981.

REPÚBLICA DE COLOMBIA, SECRETARÍA DE INFORMACIÓN Y PRENSA DE LA REPÚBLICA, Discursos y Mensajes del Presidente de la República Julio César Turbay Ayala, de agosto de 1980, a agosto de 1981, Bogotá, Talleres Gráficos del Banco Popular, 1982a.

REPÚBLICA DE COLOMBIA, SECRETARÍA DE INFORMACIÓN Y PRENSA DE LA REPÚBLICA, Discursos y Mensajes del Presidente de la república Julio César Turbay Ayala desde agosto de 1981, a febrero de 1982, Bogotá, Imprenta de la Presidencia de la República, $1982 b$. 
Seguridad e Ideología en Colombia, 1978-1982: análisis crítico del discurso de...

\section{Fuentes secundarias}

\section{Libros}

CAJAS SARRIA, Mario Alberto, La Corte Suprema controla la reforma constitucional (1978-1990), Cali, Universidad Icesi, 2011.

CAJAS SARRIA, Mario Alberto, LÓPEZ MEDINA, Diego Eduardo, El control judicial a la reforma constitucional: Colombia, 1910-2007, Cali, Universidad Icesi, 2011.

FALS BORDA, Orlando, GÚZMAN, Germán y UMAÑA LUNA, Eduardo, La Violencia en Colombia, Bogotá, Editorial Taurus, 2005.

FOUCAULT, Michel, El orden del discurso. [Traducción de Alberto González Troyano], Lección inaugural en el Collège de France, Buenos Aires, Tusquets editores, 1992.

LEAL BUITRAGO, Francisco, La Seguridad de la Inseguridad. Colombia 19582005, Bogotá, Editorial Planeta, 2006.

MORGENTHAU, Hans, Politica entre las naciones, Buenos Aires, Grupo editorial latinoamericano, 1986.

MORGENTHAU, Hans, Escritos sobre politica internacional, Madrid, Editorial Tecnos, 1990.

OROZCO ABAD, Iván, Combatientes, rebeldes y terroristas. Guerra y derecho en Colombia, Bogotá, Instituto de Estudios Políticos y Relaciones InternacionalesUniversidad Nacional de Colombia-Temis, 1992.

PÉCAUT, Daniel, Crónica de cuatro décadas de política colombiana, Bogotá, Editorial Norma, Colección Vitral, 2006.

POSADA VIANA, Alfredo y MATALLANA ESLAVA, José Iván, Estado de Sitio y Legalidad Marcial en Colombia, Bogotá, Pontificia Universidad Javeriana, 1987.

ROMERO HERRERA, Joaquín, Evolución institucional de la política de seguridad y defensa, su creación, regulación y ejecución, Bogotá, Universidad de los Andes, 2006.

ROUQUIE, Alain, El Estado Militar en América Latina, México, Siglo XXI, 1984.

SALAMANCA, José Manuel, Violencia Politica y Modelos Dinámicos: un estudio sobre el caso colombiano, Colombia, Editorial Alberdania, 2007. 
STUDER, Robert William, The Colombian army: political aspects of its role, Los Ángeles, Estados Unidos, University of Southern California, 1975.

WÆVER, Ole, BUZAN, Barry y DE WILDE Jaap, Security: a new framework for analysis, Dinamarca, Lynne Rienner Publishers, 1998. Segunda edición 2009.

\section{Capítulos de libros}

BETHENCOURT, María y AMODIO, Emanuele, "Lenguaje, ideología y poder", Caracas: Instituto internacional para la educación superior en América Latina y el Caribe (IESALC)-Unesco, 2006. Serie: Desarrollo del lenguaje y la comunicación, 2, pp.1-89.

GILHODÉS, Pierre, "El ejército colombiano analiza la violencia”, en SÁNCHEZ GÓMEZ, Gonzalo y PEÑARANDA Ricardo (Comp.), Pasado y presente de la violencia en Colombia, Medellín, La Carreta Histórica, 2007, pp. 297-318.

KEOHANE, Robert Owen, "Theory of world politics: structural realism and beyond", en KEOHANE, Robert (Ed.), Neorrealismo and Its Critics, Estados Unidos, Columbia University Press, 1986.

LEAL BUITRAGO, Francisco, "Surgimiento, Auge y Declinación de la Doctrina de Seguridad Nacional en América Latina y Colombia", en LEAL BUITRAGO, Francisco, El oficio de la guerra. La seguridad nacional en Colombia, Bogotá, TM Editores-IEPRI-Universidad Nacional de Colombia, 1994.

SCHIMITT, Carl, "Sobre la relación de los conceptos de guerra y enemigo", en El concepto de lo político, Madrid, Alianza Editorial, 1999.

WÆVER, Ole, "Securitization and desecuritización”, en LIPSCHUTZ, R. (Ed.), On Security, Estados Unidos, Columbia University Press, 1995, pp. 46-86.

\section{Artículos}

BUENO GÓMEZ, Noelia, "Crítica de la ideología de Marx", en Eikasia. Revista de Filosofía, Vol. III, No. 13, 2007, pp. 45-90.

BUZAN, Barry, "People, States \& Fear: An Agenda for International Security Studies in the post-cold War Era. Introducción y Capítulo 10", en Revista Académica de Relaciones Internacionales, No. 9, 2008, pp. 1-53.

CORREDOR, Fernando, "Colombia: la democratización del régimen y sus obstáculos”, en Nueva Sociedad, No. 69, 1983, pp. 141-150.

COTTE POVEDA, Alexander, "Una explicación de las causas económicas de la violencia en Colombia”, en Colombia Revista de Investigación, Vol. 7, No. 1, 2007, pp. 90-102. 
DAROS, William, “¿Libertad, igualdad y justicia: son incompatibles? ¿Para qué educar?", en Revista de la Facultad de Ciencias Sociales y Jurídicas de Elche, Vol. I, No. 8, 2012, pp. 99-123.

DIAZ-CALLEJAS, Apolinar, "El Estado de sitio ante la Constituyente colombiana", en Nueva Sociedad, No. 112, 1991, pp. 66-72.

LEAL BUITRAGO, Francisco, "La Doctrina de Seguridad Nacional: Materialización de la Guerra Fría en América del Sur”, en Revista de Estudios Sociales, No. 15, 2003, pp. 74-87.

JIMÉNEZ, Catalina, “Aplicación e instrumentalización de la Doctrina de Seguridad Nacional en Colombia (1978-1982): efectos sobre la temática de derechos humanos", en Reflexión Política, Vol. 11, No. 2, 2009, pp. 158-174.

MØLLER, Bill Norge, "Conceptos sobre seguridad: nuevos riesgos y desafíos", en Desarrollo Económico: Revista de Ciencias Sociales, Vol. 36, No. 143, 1996, pp. 769-792.

OROZCO RESTREPO, Gabriel, "El aporte de la escuela de Copenhague a los estudios de seguridad", en Revista Fuerzas Armadas y Sociedad, Vol. 20, No. 1, 2006, pp. 141-162.

PARDO ABRIL, Neyla Graciela, "Análisis Crítico del Discurso: un acercamiento a las representaciones sociales”, en Forma y Función, No. 12, 1999, pp. 63-81.

PARDO ABRIL, Neyla Graciela y RODRÍGUEZ, Aleyda, "Discurso y Contexto: cognición y subjetividad”, en Discurso \& Sociedad, Vol. 3, No. 1, 2009, pp. 202-219.

PARADA SANABRIA, Pompeyo José, "El proceso político colombiano durante el gobierno de Julio César Turbay Ayala”, en Eleuthera, No. 7, 2012, pp. 135-166.

PUERTA HENAO, Catalina María, "Discurso político y violencia en Colombia", en Estudios de Derecho, Vol. 65, No. 145, 2008, pp. 190-220.

RAMÍREZ, Luis Jairo, "Lo que va del Estatuto de Seguridad a la Política de Seguridad Democrática", en Boletín Actualidad Colombiana, No. 416, 2005.

RAMÍREZ BACCA, Renzo y JIMÉNEZ PATIÑO, Hernán David, “Guerra y paz: una revisión conceptual. Una interpretación para el caso colombiano”, en Historia Caribe, Vol. IX, No. 24, 2014, pp. 163-197.

SISCO MARCANO, Claudia y CHACÓN MALDONADO, Olaguér, "Barry Buzan y la teoría de los complejos de seguridad", en Revista Venezolana de Ciencia Política, No. 25, 2004, pp. 125-146. 
VAN DIJK, Teun, "Semántica del discurso e ideología”, en Discurso \& Sociedad, Vol. 2, No. 1, 2008, pp. 201-261.

VELÁSQUEZ RIVERA, Edgar de Jesús, "Historia de la Doctrina de Seguridad Nacional”, en Convergencia, Año 9, No. 27, 2002, pp. 11-39.

WÆVER, Ole, "Politics, security, theory", en Security Dialogue, Vol. 42, Nos. 4-5, 2011, pp. 465-480.

\section{Publicaciones en internet}

OCHOA GAUTIER, Ana María, "Sobre el estado de excepción como cotidianidad: cultura y violencia en Colombia", en CLACSO, (Ed.), La cultura en las crisis latinoamericanas, Buenos Aires, CLACSO, Consejo Latinoamericano de Ciencias Sociales Editorial, 2004, pp. 17-42, http://biblioteca.clacso.edu.ar/clacso/ gt/20100918084454/2ochoa.pdf

\section{Tesis}

OLARTE NIÑO, Tamanai, Estado, políticas de seguridad y derechos humanos en Colombia 1978-1982 y 2002-2006, Monografía para optar al título de especialista en Derechos Humanos, Bogotá, ESAP, 2008.

SCHROEDER GONZÁLEZ, Cristian, La influencia de la Participación de Colombia en la Guerra de Corea en la construcción de la nueva mentalidad del ejército entre 1951 hasta 1982, Monografía para optar al título de Politólogo, Bogotá, Universidad Colegio Nuestra Señora del Rosario, 2009.

\section{Otros}

NIETO ORTIZ, Pablo Andrés, ¿Subordinación o autonomía? El ejército colombiano, su relación política con el gobierno civil y su configuración en la violencia, 19531990, Informe final del concurso: El papel de las fuerzas armadas en América Latina y el Caribe, Programa Regional de Becas CLACSO, 2004. 